\title{
STUDENTS' MISCONCEPTIONS ABOUT THE NATURE OF MATTER AND HOW IT IMPAIRS BIOCHEMISTRY LEARNING
}

\author{
Montagna, E., Sales A.M.S., Medeiros, M.L. \\ Núcleo de Ensino e Pesquisa em Educação e Saúde (NEPES), Faculdade de \\ Medicina do ABC, Santo André, SP, Brazil.
}

Introduction: It is widely known that misconceptions impairs student's learning. IUBMB proposed a concept inventory which defines biochemistry's teaching scope. Even though it is known that many of them are subject of misconceptions by students, we collected informal data suggesting a deeper and most pervasive misconception related to the students' perceptions about what is and is not a molecule through their classroom statements and tests. We hypothesize that students' impairments on biochemistry learning possibly come from failure to assume that names are related to well defined molecules indicating lack of matter's representative levels of integration.

Objectives The present work aims to detect in freshmen students' misconceptions about the chemical nature of main small and macromolecules which potentialy impairs biochemistry learning.

Materials and methods: A list of assertions about real life situations involving and citing main biomolecules - ATP, DNA, protein, lipid, carbohydrate, enzyme, hormon, vitamin were mixed with other containing vague common terms - toxin, transgenic, healthy, unwanted elements, chemical compound - not suggesting hazardous situations in order to capture students' impressions. More than 150 students from five courses in three different higher education institutions answered true or false on 35 assertions.

Results and discussion: More than $70 \%$ of students had more than $80 \%$ error in this task designed to be not tricky, misleading or with unpreviously studied concepts.

Results suggests students do not understand compounds as molecules but as entities unrelated to real life situations; on the other hand vague terms triggers a negative perception not necessarily related to harm or hazardous situations. We suggest that it is originated by poor scientific literacy from previous scholarity as well as lack of criteria on media vehicles about the topics here cited.

Conclusion: We conclude that many misconceptions on biochemistry topics come from students' assumptions which arises at the biochemistry course.

Key-words: Misconceptions; Scientific Literacy; Integration of representative levels.

Acknowledgements: CAPES, Projeto Pró-Ensino na Saúde (process number 035/2010); NEPES-FMABC. 